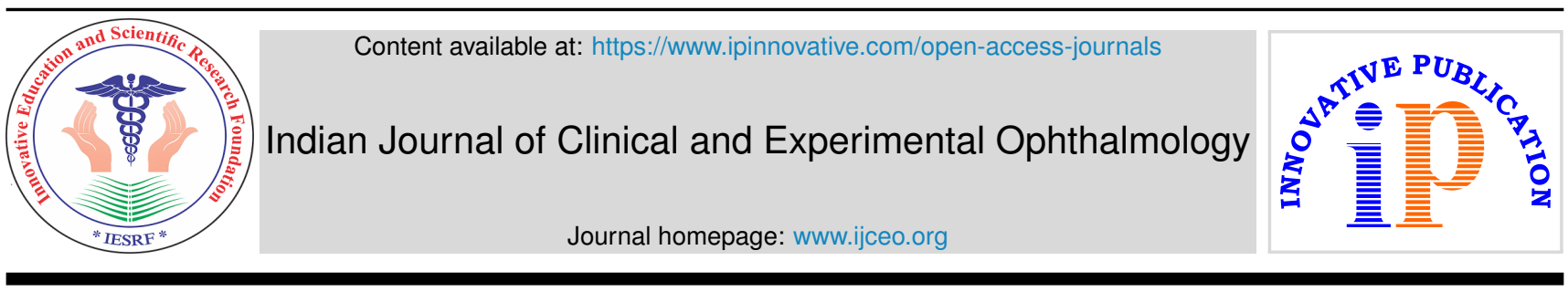

\title{
Editorial
}

\section{New advances in treatment of dry eye disease}

\author{
Rajendra P Maurya ${ }^{1} *$, Shivangi Singh ${ }^{2}$ \\ ${ }^{1}$ Regional Institute of Ophthalmology, Institute of Medical Sciences, Banaras Hindu University, Varanasi, Uttar Pradesh, India \\ ${ }^{2}$ Motilal Nehru Medical College, Prayagraj, Uttar Pradesh, India
}

\section{A R T I C L E I N F O}

Article history:

Received 23-12-2021

Accepted 27-12-2021

Available online 03-01-2022

\begin{abstract}
This is an Open Access (OA) journal, and articles are distributed under the terms of the Creative Commons Attribution-NonCommercial-ShareAlike 4.0 License, which allows others to remix, tweak, and build upon the work non-commercially, as long as appropriate credit is given and the new creations are licensed under the identical terms.

For reprints contact: reprint@ipinnovative.com
\end{abstract}

Dry eye disease (DED) is most common quality-of-life and activity-limiting disease and also requires long term drug compliance from patients. It is a multifactorial disorder of the tear film and ocular surface which is associated with tear film instability \& hyperosmolarity of tear film causing ocular surface inflammation \& damage. ${ }^{1,2}$ Patients with DED most commonly presents with symptoms which include dryness of eye, itching, burning, recurrent redness and sand corn sensation. ${ }^{3,4}$ It is more prevalent in women than in men and several studies have shown that sex and gonadal hormones have a major influence on the regulation of homeostasis of the ocular surface and quality of tear. ${ }^{5}$

The approach to the management of DED has undergone drastic changes over the past 15 years. Treatment of DED mainly depends upon the type of dry eye (aqueous deficient dry eye, evaporative dry eye or a combination of both). Other factors which determines the modality of treatment is the severity of symptoms. Proper evaluation of severity of symptoms and follow-up of patient for monitoring of treatment response and compliance of patients for treatment is necessary. These are possible by quantifying the volume $\&$ stability of tear film which is usually done by measuring tear meniscus height under slit lamp \& tear film breakup time (TBUT). Another parameter which should be quantified is tear secretion rate, which is usually done by doing Schirmer test. Degree of ocular surface damage due

\footnotetext{
* Corresponding author.

E-mail address: editorijceo@gmail.com (R. P. Maurya).
}

to DED is assessed by doing flourescin staining, rose bengal and lissamine green staining test. In case of mild DED tear supplements or lubricant drops may be sufficient but for severe and progressive dry eye nutritional supplements (omega-3 essential fatty acids), topical anti-inflammatory/ immunosuppresor and secretagogues etc. may be required. The lacrimal punctum plug can also be used after control of inflammatory component of disease. To control severe ocular surface damage one can use therapeutic scleral contact lens. Use of topical autologous serum and partial tarsorrhaphy is reserved for severe cases of DED not responding to more standard modes of therapy. ${ }^{1}$

The following drugs are current and most commonly recommended for treatment of DED:

Tear supplements are the first line of therapy for DED used for volume replacement and lubrication. The main ingredient in tear supplement is viscous agent. Corboxymethylcellulose and hydroxymethylcellulose are common base polymer in tear supplements. Hyaluronic acid is a highly viscous agent having surface coating property. Certain tear supplements contain castor oil which mimics the lipid components of tear and retards evaporation. In order to prevent ocular toxicity preservative (Benzalkonium chloride \& EDTA etc) free tear supplements are preferred.

DED being chronic condition requires long acting lubricants. The hydroxypropyl cellulose insert (Lacrisert) is best option for long-acting ocular surface lubricants. Chitosan- $\mathrm{N}$-acetylcystine (Lacrimera) is new biopolymer 
which forms a protective glycocalyx layer on the ocular surface and provides a 24 hour ocular surface retention. ${ }^{3}$ Chitosan which is derived from chitin (a component of cell wall of fungi / exoskeleton of arthropods) has mucoadhesive property and it also has thiol groups form $\mathrm{N}$-acetylcystine further enhance the stabilization of the polymer-mucin network on the ocular surface. ${ }^{6,7}$

Current studies revealed that DED is associated with a local inflammatory process on the ocular surface. ${ }^{8,9}$ Topical anti-inflammatory drugs are highly recommended in treatment of Sjogren syndrome. Several prospective studies have shown clinical benefits of short term use of topical corticosteroid in moderate to severe keratoconjunctivitis sicca (KCS). ${ }^{8,9}$ Lee et al reported that $0.1 \%$ topical prednisolone drop decreased nerve growth factor which is elevated in dry eye related ocular inflammation. ${ }^{10}$ However long term use of topical steroid for KCS is not recommended because it can lead to complications such as glaucoma and subcapsular cataract etc. It has also been reported that topical cyclosporine-A $(0.05 \%$ OR $0.1 \%)$ is highly effective in aqueous deficient dry eye in Sjogren's syndrome. Cyclosporine $-\mathrm{A}$ has anti-inflammatory effect by lowering formation of pro-inflammatory cytokines. It inhibits calcium dependent interleukin-2 (IL-2) production and hence inhibit the lymphocytic proliferation. ${ }^{5,11}$

Topical Hydroxychloroquine (HCQ) has also been tried in primary Sjogren's syndrome. HCQ acts by decreasing the level of tear fluid B-Cell activating factor (BAFA) in tear film, which play a vital role in the pathogenesis of primary Sjogren's syndrome. It usually improves both subjective and objective manifestations of dry eye. HCQ also improves salivary gland function by inhibitory effect on glandular cholinesterase. ${ }^{12}$

Diquafosol tetrasodium (purinergic receptor agonists) is newer drug which may restore physiological lacrimal secretion and tear flow in DED. It is a highly water soluble dinucleotide that acts by targeting $\mathrm{P}_{2} \mathrm{Y}_{2}$ receptors present on ocular surface. Diquafosol tetrasodium increases fluid transport, mucin secretion from conjunctival cells and also stimulates lipid production in DED patients and hence increases tear film stability. Takamura et al in their randomized, double-masked comparison study comparing efficacy of 3\% Diquafosol tetrasodium and $0.1 \%$ sodium hyaluronate ophthalmic solutions in 286 DED patient. In this study it was found that $3 \%$ Diquafosol tetrasodium was significantly superior to $0.1 \%$ sodium hyaluronate in terms of improvement in rose bengal staining. Takamura et al also demonstrated that topical Diquafosol tetrasodium therapy $>4$ months was effective in cases of meibomian gland dysfunction. ${ }^{13}$ It increases lipid secretion from meibomian gland. Recent studies suggested that combination of sodium hyaluronate and Diquafosol tetrasodium is good option to improve dry eye symptoms after refractive surgery ${ }^{14}$ and in patients of Sjogren's syndrome. ${ }^{15}$

Other secretagogue therapy used in DED are oral pilocarpine, cevimeline and rebamipide. Rebamipide is an amino acid derivative of 2-(H)-quinolone. It increases production of mucin from conjunctival goblet cell, mediated by MUC1 and MUC4 gene expression. It also suppress the production of inflammatory cytokines like IL8, TNF $\alpha$ and NFkB. ${ }^{16}$

\section{References}

1. Foulks GN, Forstot SL, Donshik PC, Forstot JZ, Goldstein MH. Clinical guidelines for management of dry eye associated with Sjogren disease. Ocul Surf. 2015;13(2):118-32.

2. Maurya RP. Dry eye disease : An overview. Ind J Clin Exp Ophthalmol. 2018;4(4):433-4.

3. Nepp J, Knoetzl W, Prinz A, Hoeller S, Prinz M. Management of moderate to severe dry eye disease using chitosan-N-acetylcysteine (Lacrimera) eye drops: a retrospective case series. Int Ophthalmol. 2020;40(6):1547-52.

4. Maurya RP, Singh VP, Chaudhary S, Roy M, Srvastav T, Rajan M. Prevalence of severe dry eye disease in postmenopausal women in North India: A teaching hospital study. Indian J Obst Gynecol Res. 2019;6(1):94-6.

5. Maurya RP, Singh V, Gupta A, Singh VP, Kumar A, Yadav A. Dry eye disease associated with primary Sjogren's syndrome: An update. Ind J Clin Exp Ophthalmol. 2021;7(2):259-69.

6. Felice F, Zambito Y, Belardinelli E, Fabiano A, Santoni T, Stefano RD. Effect of different chitosan derivatives on in vitro scratch wound assay: a comparative study. Int J Biol Micromol. 2015;76:236-41.

7. Zhang H, Qadeer A, Chen W. In situ gelable interpenetrating double network htdrogel formulated from binary componants: thiolated chitosan and oxidized dextran. Biomacromol. 2011;12(5):1428-37.

8. Marsh P, Pflugfelder SC. Topical nonpreserved methylprednisolone therapy for keratoconjunctivitis sicca in Sjogren syndrome. Ophthalmology. 1999;106(4):811-6.

9. Yang C, Sun WY. A clinical study of the efficacy of topical corticosteroid on dry eye. J Zhijung Univ Sci B. 2006;7:675-8.

10. Lee HK, Fyu IH, Seo KY. Topical 0.\% prednisolone lowers nerve growth factor expression in keratoconjunctivitis sicca patients. Ophthalmology. 2006;13:L198-205.

11. Deveer H, Kobak S. The efficacy of topical $0.05 \%$ cyclosporine A in patients with dry eye disease associated with Sjögren's syndrome. Int Ophthalmol. 2014;34(5):1043-8.

12. Yavuz S, Asfuroglu E, Bicakcigli M, Toker E. Hydroxychloroquine improves dry eye symptoms of patient with primary Sjogren's syndrome. Rheumatol Int. 2011;31(8):1045-9.

13. Takamura E, Tsubota K. A randomized doublemasked comparison study of diquafosol versus sodium hyaluronate ophthalmic solutions in dry eye patients. Br J Ophthalmol. 2012;96(10):1310-5.

14. Toda I, Ide T, Fukumoto T. Combination therapy with diquafosol tetrasodium and hyaluronate in patient with dry eye after laser in situ keratomileusis. Am J Ophthalmol. 2014;157(3):616-22.

15. Kamiya K, Nakanishi $M$. Clinical evaluation of the additive effect of diquafosol tetrasodium on sodium hyaluronate monotherapy in patients with dry eye syndrome: a prospective, randemised , multicentric study. Eye (Lond). 2012;26(10):1363-8.

16. Dorennavar L, Maurya RP, Singh VP, Singh MK, Sharma K, Sharma $\mathrm{R}$. The role of rebamipide ophthalmic suspension in management of dry eye disease. Ind J Clin Exp Ophthalmol. 2015;1(4):191-6.

\section{Author biography}




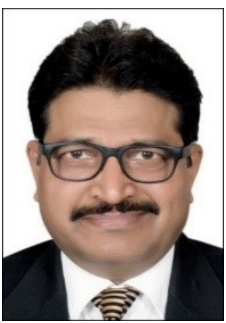

Rajendra P Maurya, (MBBS, MS, Ph.D), Editor in Chief IJCEO, Associate Professor \& $\mathrm{I} / \mathrm{c}$ Orbit, Ocular Oncology and Oculoplasty Unit Regional Institute of Ophthalmology, Institute of Medical Sciences, Banaras Hindu University, Varanasi, (UP), India

E-mail: editorijceo@gmail.com,

mauryarp_bhu@yahoo.com
Shivangi Singh, Senior Resident

Cite this article: Maurya RP, Singh S. New advances in treatment of dry eye disease. Indian J Clin Exp Ophthalmol 2021;7(4):605-607. 